\title{
Discrepancy between endoscopic and pathological ulcerative findings in clinical intramucosal early gastric cancer
}

\author{
Yohei Yabuuchi $^{1}$ - Kohei Takizawa ${ }^{1} \cdot$ Naomi Kakushima $^{2} \cdot$ Noboru Kawata $^{1} \cdot$ Masao Yoshida $^{1}$ - Yoichi Yamamoto ${ }^{1}$. \\ Yoshihiro Kishida ${ }^{1}$. Sayo Ito $^{1}$ - Kenichiro Imai ${ }^{1} \cdot$ Hirotoshi Ishiwatari $^{1} \cdot$ Kinichi Hotta $^{1} \cdot$ Hiroyuki Matsubayashi ${ }^{1}$. \\ Etsuro Bando ${ }^{3} \cdot$ Masanori Terashima $^{3} \cdot$ Takashi Sugino $^{4} \cdot$ Hiroyuki Ono $^{1}$
}

Received: 22 October 2020 / Accepted: 16 December 2020 / Published online: 5 January 2021

(C) The International Gastric Cancer Association and The Japanese Gastric Cancer Association 2021

\begin{abstract}
Background Ulcerative finding (UL) is one of the factors that define the indication and curability of endoscopic resection (ER) in early gastric cancer (EGC). Discrepancies between endoscopic UL (cUL) and pathological UL (pUL) sometimes occur in clinical practice. The aim of this study was to investigate the discrepancy rate in UL diagnosis and the risk factors associated with such discrepancies.

Methods Patients with clinical intramucosal (cT1a) EGC who underwent ER or surgery between September 2002 and December 2017 were analyzed. The proportion of cUL-negative (cUL0) lesions that were identified as pUL-positive (pUL1) and that of cUL-positive (cUL1) lesions that were identified as pUL-negative (pUL0) were calculated. Logistic regression analysis was performed to estimate the associations between discrepancy in UL diagnosis and clinical variables of the lesion, such as the size, histology, location, and macroscopic type.

Results In total, 5382 lesions were evaluated; 5.5\% of cUL0 lesions (256/4619) were identified as pUL1, while 38.7\% of cUL1 lesions (295/763) were pUL0. Multivariate analysis indicated that in cUL1 lesions, tumor location in the lower third of the stomach (odds ratio 3.11, 95\% confidence interval 1.90-5.08) was identified as an independent risk factor for overestimation.

Conclusions Endoscopic diagnosis of UL in cT1a EGC was overestimated in 38.7\% of lesions, especially for lesions located in the lower third of the stomach. This discrepancy should be considered in the management of cT1a EGC with UL.
\end{abstract}

Keywords Ulcerative finding $\cdot$ Early gastric cancer $\cdot$ Discrepancy $\cdot$ Endoscopic resection

\section{Introduction}

Endoscopic resection (ER) is a widely accepted standard and less invasive treatment for early gastric cancer (EGC) without lymph node metastasis since last few decades [1-3].

Yohei Yabuuchi

y.yabuuchi@ scchr.jp

1 Division of Endoscopy, Shizuoka Cancer Center, 1007 Shimonagakubo, Nagaizumi, Suntogun, Shizuoka 411-8777, Japan

2 Department of Gastroenterology and Hepatology, Nagoya University Graduate School of Medicine, Nagoya, Japan

3 Division of Gastric Surgery, Shizuoka Cancer Center, Shizuoka, Japan

4 Division of Pathology, Shizuoka Cancer Center, Shizuoka, Japan
Ulcerative finding (UL) is one of the factors that define the indication and curability of ER for intramucosal (T1a) EGC according to the Japanese gastric cancer treatment guidelines [4]. To determine a proper treatment strategy, it is necessary to determine the presence or absence of UL prior to treatment. The presence or absence of UL should be endoscopically diagnosed in principle [5] although discrepancies between endoscopic (cUL) and pathological ulcerative findings (pUL) sometimes occur in clinical practice. Thus, overestimation of cUL may lead to unnecessary surgery. However, only few studies regarding this discrepancy are known. In this study, we evaluated the discrepancy rate between cUL and pUL and identified the risk factors associated with such a discrepancy. 


\section{Methods}

\section{Patients and lesions}

In this retrospective study, a total of 5903 clinical T1a (cT1a) EGC from 5154 patients, who were treated by ER or surgery at a single tertiary cancer center in Japan from September 2002 to December 2017, were identified. The lesions excluded were those in the remnant stomach or gastric tube $(n=250)$, recurrent or remnant lesions $(n=100)$, piecemeal resection by ER $(n=38)$, and in case of missing data $(n=133)$. Therefore, 5382 lesions from 4756 patients were included in the present study. Data were extracted from prospectively maintained endoscopic and pathological reports. Written informed consent for examination and treatment was obtained from all patients before the procedure. The institutional review board of Shizuoka Cancer Center approved this study (institutional ID: J2019-111-2019-1-3).

\section{Endoscopic examination}

A close endoscopic examination prior to the treatment was performed to determine the therapeutic strategy for EGC. In this examination, clinical factors such as location, macroscopic type, size, depth of invasion, histological type, and presence or absence of UL were evaluated. Tumor location in the longitudinal axis of the stomach was classified into three parts: upper, middle, and lower third. Tumor location in the cross-sectional circumference of the stomach was divided into four equal parts: lesser curvature, anterior wall, greater curvature, and posterior wall. Circumferential involvement was recorded as the circumference. The macroscopic type was categorized into three subgroups: elevated type (0-I, 0-IIa, or a combination of these two types), flat/ depressed type (0-IIb, 0 -IIc, 0 -III, or a combination of these three types), and mixed type (a combination of elevated and flat/depressed types). The histological type of EGC prior to treatment was based on histopathological diagnosis using biopsy specimens. When biopsy specimens showed mixed histology, the histological type was classified based on the predominant component. When the histopathological diagnosis using biopsy specimens was adenoma but the endoscopic diagnosis was cancer, the lesion was classified as a differentiated type. For the ULs, cUL-positive (cUL1) was determined when findings of evident ulcer of active, healing, or scarring in the lesion were noted [6]. UL in the active stage was defined as an open ulcer covered with slough and surrounded by edematous mucosa (Fig. 1a). UL in the healing stage was defined as shallow erosion covered with slough and reddish regenerating epithelium (Fig. 1b). UL in the scarring stage was defined as a lesion with fold convergence and/or reddish regenerating epithelium (Fig. 1c). The examiner diagnosed cUL while the other endoscopists reviewed the images at a pre-treatment conference, and if the diagnosis was considered to be apparently incorrect, it was corrected. If the images from the previous hospital prior to biopsy were available, cUL was evaluated with reference to them. In the subgroup analysis, cUL1 was divided into three stages described above. If images of different ulcer stages were available for multiple examinations, the most advanced stage was selected: if it contained images of UL in the active stage, it was judged as the active stage, and if it contained no images of UL in the active stage but images in the healing stage, it was judged as the healing stage.

\section{Histological evaluation}

The resected specimen was placed on a flat board, pinned at the edges, and fixed in buffered formalin solution. The endoscopically resected specimen was sectioned serially at 2-3-mm intervals, whereas the surgically resected specimen was sectioned serially at 5-mm intervals. Histological evaluation was performed in accordance with the Japanese

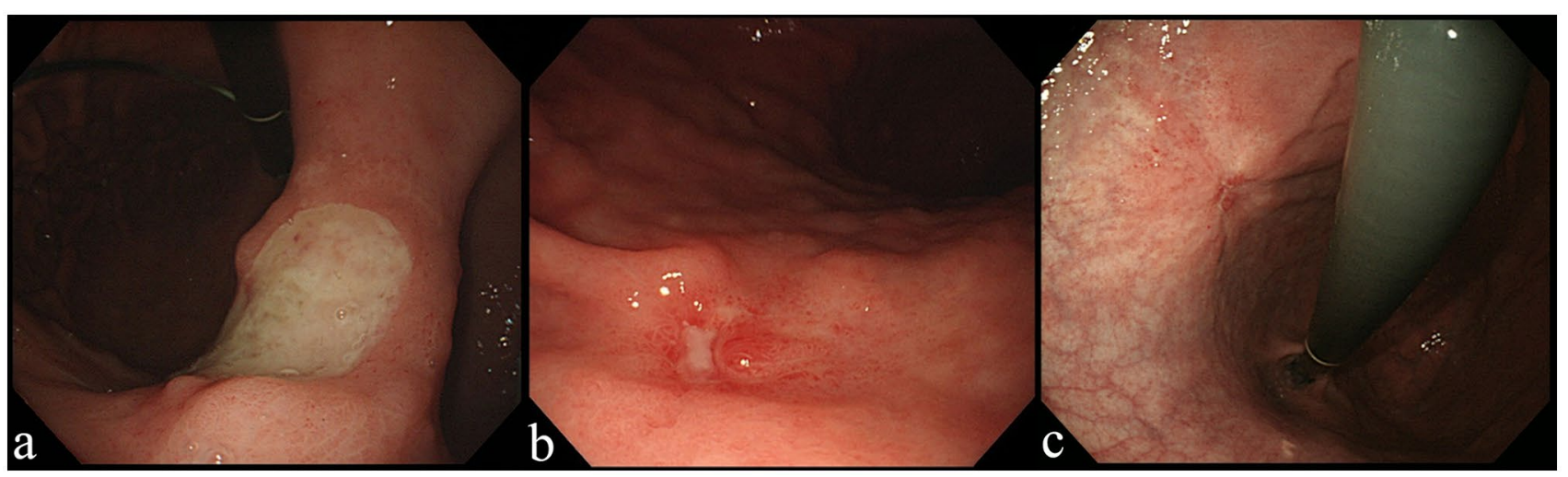

Fig. 1 Representative images of endoscopic ulcerative findings in early gastric cancer. a Active stage; b Healing stage; $\mathbf{c}$ scarring stage 
classification of gastric carcinoma [7]. All specimens were reviewed by at least two experienced pathologists. Regarding the diagnosis of UL, pUL-positive (pUL1) was defined as (1) rupture of muscularis mucosae or irregular thickening and lining of the muscularis mucosae with myofibrosis and (2) fibrosis in the submucosal or deeper layer exceeding the range of muscularis mucosae rupture (Fig. 2). Fibrosis restricted to a small area of less than $5 \mathrm{~mm}$ beneath the muscularis mucosae was diagnosed as a biopsy-derived scar rather than a UL (Fig. 3).

\section{Statistical analysis}

Categorical variables were reported as counts and percentages, and continuous variables were summarized by their medians and interquartile ranges (IQRs). Univariate and multivariate logistic regression analyses, with corresponding odds ratios (ORs) and $95 \%$ confidence intervals (CIs) were performed to identify risk factors associated with discrepancies between cUL and pUL. All reported $p$ values were two-sided, and $p<0.05$ was considered significant. All statistical analyses were performed using $\mathrm{R}$ version 3.2.2 (The R Foundation for Statistical Computing, Vienna, Austria).

\section{Results}

\section{Clinicopathological characteristics}

The clinicopathological characteristics of the 4756 patients with 5382 cT1a EGC are summarized in Table 1.
Fig. 2 Representative image of pathological ulcerative finding positive

Fig. 3 Representative image of pathological biopsy-derived scar
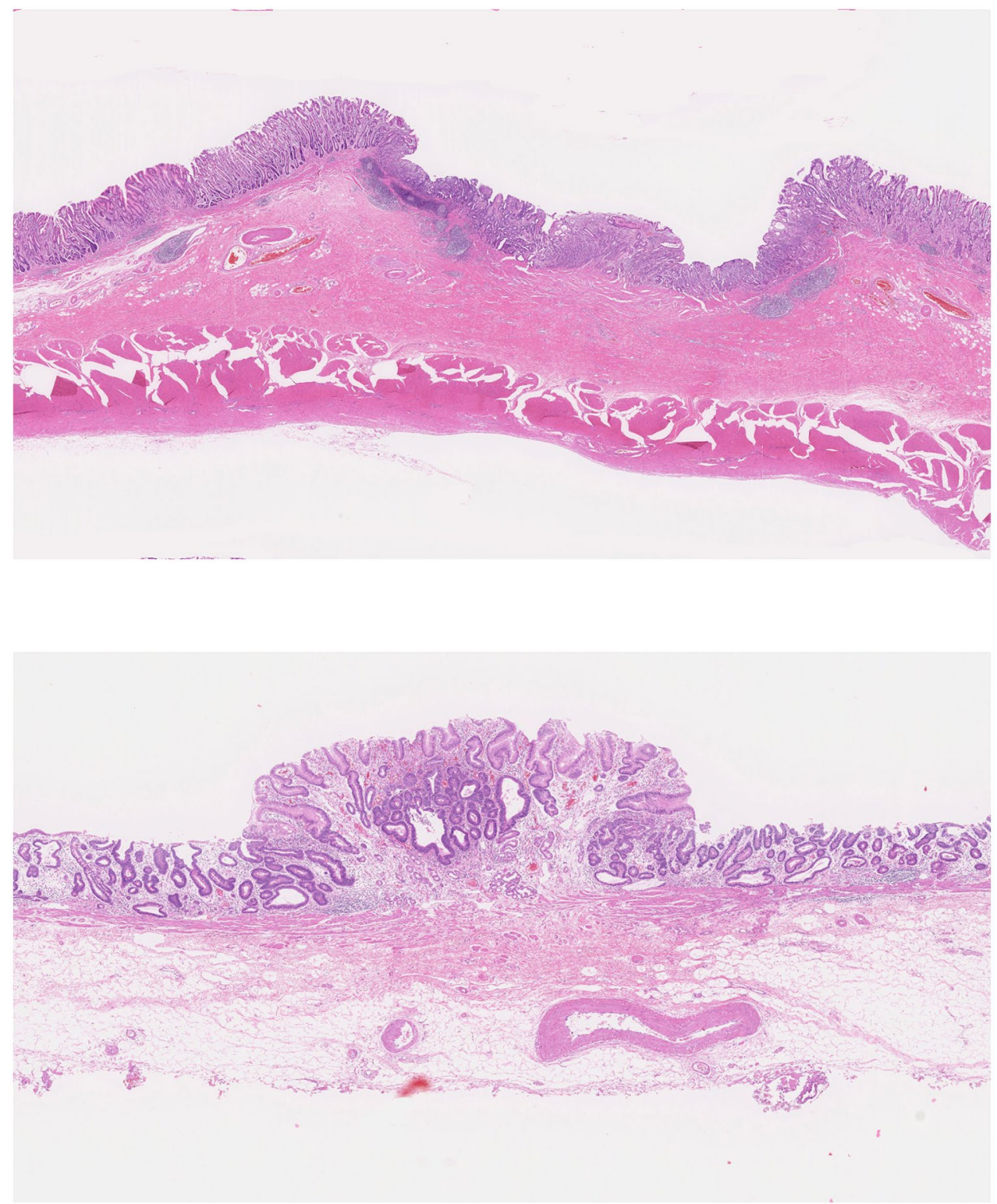
The median age was 71 years (IQR, 64-77), most of the patients were men $(73.8 \%)$, and most of the lesions were treated with ER (89.2\%). The middle third was most common for location in the longitudinal axis $(44.3 \%)$, and the lesser curvature for location in the cross-sectional circumference $(40.9 \%)$. The predominant macroscopic type was the flat/depressed type (63.0\%). The endoscopic median tumor size was $15 \mathrm{~mm}$ (IQR, 10-22), while the pathological median size was $17 \mathrm{~mm}$ (IQR, 11-28). Regarding the histological type, most lesions were categorized as differentiated type for both diagnoses using biopsy specimens $(88.5 \%)$ and resected specimens $(88.0 \%)$. With respect to the depth of invasion, $7.5 \%, 8.4 \%$, and $0.4 \%$ of the lesions pathologically invaded the superficial submucosa, deep submucosa, and muscularis propria or deeper, respectively. As for ULs, 763 lesions (14.2\%) were diagnosed as cUL1, whereas 723 lesions (13.4\%) were diagnosed as pUL1.

\section{Accuracy of endoscopic diagnosis of ulcerative findings}

The diagnostic performance of cUL in cT1a EGC is shown in Table 2. Among 763 cUL1 lesions, 468 (61.3\%) were diagnosed as pUL1, while 295 (38.7\%) were diagnosed as pUL0 (overestimation group). Among the 4619 cUL0 lesions, 4363 (94.5\%) were diagnosed as pUL0, while 256 (5.5\%) were diagnosed as pUL1 (underestimation group). The accuracy, sensitivity, and specificity of the endoscopic diagnosis of UL were $89.8 \%, 64.6 \%$, and $93.7 \%$, respectively. The positive and negative predictive values were $61.3 \%$ and $94.5 \%$, respectively.

\section{Risk factors associated with overestimation of endoscopic ulcerative findings}

The results of univariate and multivariate analyses of risk factors related to overestimation of cUL are shown in Table 3. Multivariate analysis revealed that tumor location in the lower third (OR 3.09, 95\% CI 1.89-5.05) was an independent risk factor for overestimation of cUL.

\section{Risk factors associated with underestimation of endoscopic ulcerative findings}

The results of univariate and multivariate analyses of risk factors related to underestimation of cUL are shown in Table 4. Multivariate analysis revealed that tumor size larger than $20 \mathrm{~mm}$ (OR 2.07, 95\% CI 1.41-3.02 in 21-30 mm; OR 2.58, 95\% CI $1.68-3.97$ in $\geq 31 \mathrm{~mm}$ ), tumor location in the upper (OR 1.63, 95\% CI 1.13-2.35) and middle (OR 1.52, 95\% CI 1.12-2.05) thirds, and
Table 1 Clinicopathological characteristics of 4756 patients with 5382 cT1a early gastric cancer

\begin{tabular}{|c|c|}
\hline Age, years, median (IQR) & $71(64-77)$ \\
\hline \multicolumn{2}{|l|}{ Sex, $n(\%)$} \\
\hline Male & $3508(73.8)$ \\
\hline Female & $1248(26.2)$ \\
\hline \multicolumn{2}{|l|}{ Treatment method, $n(\%)$} \\
\hline ER & $4803(89.2)$ \\
\hline Surgery & $579(10.8)$ \\
\hline \multicolumn{2}{|l|}{ Location $1, n(\%)$} \\
\hline Upper third & 927 (17.2) \\
\hline Middle third & $2383(44.3)$ \\
\hline Lower third & $2072(38.5)$ \\
\hline \multicolumn{2}{|l|}{ Location $2, n(\%)$} \\
\hline Lesser curvature & $2200(40.9)$ \\
\hline Anterior wall & $1032(19.2)$ \\
\hline Greater curvature & $915(17.0)$ \\
\hline Posterior wall & $1220(22.7)$ \\
\hline Circumference & $15(0.3)$ \\
\hline \multicolumn{2}{|l|}{ Macroscopic type } \\
\hline Flat/depressed & $3388(63.0)$ \\
\hline Elevated & $1605(29.8)$ \\
\hline Mixed & $389(7.2)$ \\
\hline Clinical tumor size, mm, median (IQR) & $15(10-22)$ \\
\hline \multicolumn{2}{|l|}{ Clinical tumor size, $\mathrm{mm}, n(\%)$} \\
\hline $1-10$ & $1877(34.9)$ \\
\hline $11-20$ & $2083(38.7)$ \\
\hline $21-30$ & $853(15.8)$ \\
\hline $31-$ & $569(10.6)$ \\
\hline Pathological tumor size, mm, median (IQR) & $17(11-28)$ \\
\hline \multicolumn{2}{|l|}{ Pathological tumor size, $\mathrm{mm}, n(\%)$} \\
\hline $1-10$ & $1324(24.6)$ \\
\hline $11-20$ & $1886(35.0)$ \\
\hline $21-30$ & $1036(19.2)$ \\
\hline $31-$ & $1136(21.1)$ \\
\hline \multicolumn{2}{|l|}{ Clinical histological type, $n(\%)$} \\
\hline Differentiated & $4761(88.5)$ \\
\hline Undifferentiated & $621(11.5)$ \\
\hline \multicolumn{2}{|l|}{ Pathological histological type, $n(\%)$} \\
\hline Differentiated & $4738(88.0)$ \\
\hline Undifferentiated & $644(12.0)$ \\
\hline \multicolumn{2}{|l|}{ Pathological tumor depth, $n(\%)$} \\
\hline $\mathrm{T} 1 \mathrm{a}(\mathrm{M})$ & 4501 (83.6) \\
\hline T1b1 (SM1) & $406(7.5)$ \\
\hline T1b2 (SM2) & $454(8.4)$ \\
\hline $\mathrm{T} 2(\mathrm{MP})$ or deeper & $21(0.4)$ \\
\hline \multicolumn{2}{|l|}{ Endoscopic ulcerative findings, $n(\%)$} \\
\hline Negative & $4619(85.8)$ \\
\hline Positive & $763(14.2)$ \\
\hline \multicolumn{2}{|l|}{ Pathological ulcerative findings, $n(\%)$} \\
\hline Negative & 4659 (86.6) \\
\hline Positive & $723(13.4)$ \\
\hline
\end{tabular}

$I Q R$ interquartile range, $E R$ endoscopic resection, $M$ mucosa, $S M I$ superficial submucosa (tumor invasion is less than $500 \mu \mathrm{m}$ from muscularis mucosae), SM2 deep submucosa (tumor invasion is $500 \mu \mathrm{m}$ or deeper from muscularis mucosae), $M P$ muscularis propria 
Table 2 Diagnostic performance of endoscopic ulcerative findings in clinical intramucosal early gastric cancer

\begin{tabular}{lllc}
\hline & & \multicolumn{2}{l}{$\begin{array}{l}\text { Pathological ulcerative } \\
\text { findings }\end{array}$} \\
\cline { 3 - 4 } & & Positive & Negative \\
\hline $\begin{array}{lll}\text { Endoscopic ulcera- } \\
\text { tive findings }\end{array}$ & Positive & 468 & 295 \\
& Negative & 256 & 4363 \\
\hline
\end{tabular}

macroscopically flat/depressed type (OR 3.30, 95\% CI 2.30-4.72) and mixed type (OR $2.43,95 \%$ CI 1.40-4.23) were independent risk factors for underestimation of cUL.

\section{Subgroup analysis according to the ulcer stage}

Of $763 \mathrm{cUL} 1$ lesions, the number of UL in the active, healing, and scarring stages was 30,146, and 587, respectively. All 30 cUL1 lesions in the active stage were diagnosed as pUL1. However, among 146 cUL1 lesions in the healing stage and 587 in the scarring stage, 74 (50.7\%) and 364 $(62.0 \%)$ were diagnosed as pUL1, respectively.

The results of univariate and multivariate analyses of risk factors related to the overestimation of cUL in the healing and scarring stages are shown in Tables 5 and 6, respectively.
In both stages, multivariate analysis revealed that tumor location in the lower third (OR 4.02, 95\% CI 1.10-14.7 in the healing stage; OR $2.79,95 \%$ CI 1.55-5.02 in the scarring stage) was an independent risk factor for overestimation.

\section{Discussion}

This study investigated the discrepancy rate between cUL and pUL and identified the risk factors associated with this discrepancy. To the best of our knowledge, this is the largest study to examine discrepancies between cUL and pUL. This study revealed that $38.7 \%$ of cUL1 in cT1a EGC were overestimated, especially for lesions located in the lower third of the stomach.

Preoperative diagnoses are not always accurate. There are several reports about discrepancies between clinical and pathological diagnoses of factors such as size [8-10], depth of invasion [11-14], and histological type [15-17]. As with these factors, discrepancies between cUL and pUL sometimes occur in clinical practice. To determine a proper treatment strategy, the presence or absence of UL must be determined during endoscopy. Park et al. [18] reported that the endoscopic definition of UL in EGC was quite different among endoscopists. The rate of overestimation was
Table 3 Univariate and multivariate analyses of risk factors for overestimation of endoscopic ulcerative findings

\begin{tabular}{|c|c|c|c|c|c|c|}
\hline & \multirow[t]{2}{*}{ Total } & \multirow[t]{2}{*}{ Discrepancy case (\%) } & \multicolumn{2}{|l|}{ Univariate } & \multicolumn{2}{|l|}{ Multivariate } \\
\hline & & & OR $(95 \% \mathrm{CI})$ & $p$ value & OR $(95 \% \mathrm{CI})$ & $p$ value \\
\hline \multicolumn{7}{|l|}{ Size (mm) } \\
\hline $1-10$ & 91 & $38(41.8)$ & 1 (Ref) & & 1 (Ref) & \\
\hline $11-20$ & 277 & $111(40.1)$ & $0.93(0.58-1.51)$ & 0.78 & $1.02(0.62-1.68)$ & 0.94 \\
\hline $21-30$ & 222 & 77 (34.7) & $0.74(0.45-1.22)$ & 0.24 & $0.83(0.50-1.40)$ & 0.49 \\
\hline 31 & 173 & $69(39.9)$ & $0.93(0.55-1.55)$ & 0.77 & $1.09(0.63-1.90)$ & 0.75 \\
\hline \multicolumn{7}{|l|}{ Histology } \\
\hline Differentiated & 585 & $224(38.3)$ & 1 (Ref) & & 1 (Ref) & \\
\hline Undifferentiated & 178 & $71(39.9)$ & $1.07(0.76-1.51)$ & 0.70 & $1.07(0.74-1.55)$ & 0.72 \\
\hline \multicolumn{7}{|l|}{ Location 1} \\
\hline Upper third & 159 & $47(29.6)$ & 1 (Ref) & & 1 (Ref) & \\
\hline Middle third & 463 & $168(36.3)$ & $1.36(0.92-2.00)$ & 0.13 & $1.40(0.94-2.10)$ & 0.10 \\
\hline Lower third & 141 & $80(56.7)$ & $3.13(1.94-5.03)$ & $<0.001$ & $3.09(1.89-5.05)$ & $<0.001$ \\
\hline \multicolumn{7}{|l|}{ Location 2} \\
\hline Lesser curvature & 337 & $116(34.4)$ & 1 (Ref) & & 1 (Ref) & \\
\hline Anterior wall & 143 & $62(43.4)$ & $1.46(0.98-2.18)$ & 0.06 & $1.35(0.89-2.05)$ & 0.16 \\
\hline Greater curvature & 97 & $46(47.4)$ & $1.72(1.09-2.72)$ & 0.02 & $1.60(0.99-2.58)$ & 0.06 \\
\hline Posterior wall & 182 & $70(38.5)$ & $1.19(0.82-1.73)$ & 0.36 & $1.27(0.86-1.88)$ & 0.23 \\
\hline Circumference & 4 & $1(25.0)$ & $0.64(0.07-6.17)$ & 0.70 & $0.33(0.03-3.35)$ & 0.35 \\
\hline \multicolumn{7}{|l|}{ Macroscopic type } \\
\hline Flat/depressed & 682 & $259(38.0)$ & 1 (Ref) & & 1 (Ref) & \\
\hline Elevated & 44 & $16(36.4)$ & $0.93(0.50-1.76)$ & 0.83 & $1.09(0.57-2.11)$ & 0.79 \\
\hline Mixed & 37 & $20(54.1)$ & $1.92(0.99-3.74)$ & 0.05 & $1.73(0.86-3.47)$ & 0.12 \\
\hline
\end{tabular}

$O R$ odds ratio, $C I$ confidence interval 
Table 4 Univariate and multivariate analyses of risk factors for underestimation of endoscopic ulcerative findings

\begin{tabular}{|c|c|c|c|c|c|c|}
\hline & \multirow[t]{2}{*}{ Total } & \multirow{2}{*}{$\begin{array}{l}\text { Discrepancy } \\
\text { case }(\%)\end{array}$} & \multicolumn{2}{|l|}{ Univariate } & \multicolumn{2}{|l|}{ Multivariate } \\
\hline & & & OR (95\% CI) & $p$ value & OR $(95 \%$ CI $)$ & $p$ value \\
\hline \multicolumn{7}{|l|}{ Size $(\mathrm{mm})$} \\
\hline $1-10$ & 1780 & $75(4.2)$ & 1 (Ref) & & 1 (Ref) & \\
\hline $11-20$ & 1802 & $93(5.2)$ & $1.25(0.92-1.71)$ & 0.16 & $1.31(0.95-1.79)$ & 0.10 \\
\hline $21-30$ & 629 & $50(7.9)$ & $1.96(1.36-2.84)$ & $<0.001$ & $2.07(1.41-3.02)$ & $<0.001$ \\
\hline 31 & 394 & $36(9.1)$ & $2.35(1.56-3.54)$ & $<0.001$ & $2.58(1.68-3.97)$ & $<0.001$ \\
\hline \multicolumn{7}{|l|}{ Histology } \\
\hline Differentiated & 4162 & $213(5.1)$ & 1 (Ref) & & 1 (Ref) & \\
\hline Undifferentiated & 443 & $41(9.3)$ & $1.88(1.32-2.66)$ & $<0.001$ & $1.16(0.80-1.69)$ & 0.44 \\
\hline \multicolumn{7}{|l|}{ Location 1} \\
\hline Upper third & 764 & $54(7.1)$ & $1.80(1.26-2.57)$ & 0.001 & $1.63(1.13-2.35)$ & 0.01 \\
\hline Middle third & 1915 & $122(6.4)$ & $1.64(1.23-2.19)$ & $<0.001$ & $1.52(1.12-2.05)$ & 0.007 \\
\hline Lower third & 1926 & $78(4.0)$ & 1 (Ref) & & 1 (Ref) & \\
\hline \multicolumn{7}{|l|}{ Location 2} \\
\hline Lesser curvature & 1857 & $112(6.0)$ & 1 (Ref) & & 1 (Ref) & \\
\hline Anterior wall & 888 & $43(4.8)$ & $0.81(0.56-1.15)$ & 0.23 & $0.85(0.59-1.23)$ & 0.40 \\
\hline Greater curvature & 814 & $35(4.3)$ & $0.70(0.47-1.02)$ & 0.07 & $0.74(0.50-1.11)$ & 0.15 \\
\hline Posterior wall & 1035 & $63(6.1)$ & $1.00(0.73-1.37)$ & 0.99 & $0.99(0.72-1.37)$ & 0.95 \\
\hline Circumference & 11 & $1(9.1)$ & $1.55(0.20-12.2)$ & 0.68 & $1.38(0.16-11.7)$ & 0.77 \\
\hline \multicolumn{7}{|l|}{ Macroscopic type } \\
\hline Flat/depressed & 2694 & $194(7.2)$ & $2.97(2.10-4.20)$ & $<0.001$ & $3.30(2.30-4.72)$ & $<0.001$ \\
\hline Elevated & 1560 & $40(2.6)$ & 1 (Ref) & & 1 (Ref) & \\
\hline Mixed & 351 & $20(5.7)$ & $2.29(1.32-3.97)$ & 0.003 & $2.43(1.40-4.23)$ & 0.002 \\
\hline
\end{tabular}

$O R$ odds ratio, $C I$ confidence interval higher for endoscopists with less endoscopic experience or no ER experience. In this study, many endoscopists performed endoscopic examinations to determine the therapeutic strategy of EGCs. However, we believe that the quality of examinations was ensured even when endoscopists with less endoscopic experience performed examinations, as the images were reviewed by experienced endoscopists at a pre-treatment conference. Regarding endoscopic findings, it was reported that fold convergence and color change were related to pUL1, with statistical significance. However, fold convergence was found in only $24.4 \%$ of pUL1 cases, and color change was observed in as many as $76.4 \%$ of pUL0 cases [19]. Mucosal break tended to be diagnosed as cUL1[18], although only half of the lesions with mucosal breaks showed pUL1 [19]. From these results, it could be understood that there was no endoscopic finding that corresponded directly to pUL and that it was difficult to accurately diagnose the presence or absence of pUL from endoscopic findings.

As for the diagnosis of UL, Japanese gastric cancer treatment guidelines described the following: "Diagnosis of UL1 is principally made based on the histological evidence of ulcerative findings. However, the histological diagnosis of UL is sometimes difficult because of a biopsy-derived scar. Thus, endoscopic and/or radiological evidence should also be taken into consideration when making a conclusive diagnosis [4]." Because the risk of lymph node metastasis in EGC was assessed using pathological factors in previous studies [20,21], pathological evaluation should be a priority for the diagnosis of UL. However, if there is a discrepancy between cUL and pUL, the pathological evaluation should be thoroughly reviewed for errors. If cUL is negative but pUL is positive, we should be careful not to misdiagnose a biopsy-derived scar as pUL. On the other hand, if cUL is positive but pUL is negative, it is necessary to consider whether we have overlooked pUL. For example, if the resected specimen does not contain submucosal layer, it is impossible to diagnose pUL. In such cases, the diagnosis of UL should be made based on cUL. To avoid such a difficult situation of pathological diagnosis, we strived to perform endoscopic submucosal dissection including sufficient submucosal layer in clinical practice. Furthermore, this study excluded cases in which the pathological evaluation of UL was difficult, such as piecemeal resection by ER and recurrent or remnant lesions. Therefore, the pathological evaluation of UL conducted in this study was considered adequate.

In this study, $5.5 \%$ of cUL0 in cT1a EGC were underestimated, whereas $38.7 \%$ of cUL1 in cT1a EGC were overestimated. The rate of underestimation was considered acceptable but the rate of overestimation was considered too high 
Table 5 Univariate and multivariate analyses of risk factors for overestimation of endoscopic ulcerative findings in the healing stage

\begin{tabular}{|c|c|c|c|c|c|c|}
\hline & \multirow[t]{2}{*}{ Total } & \multirow{2}{*}{$\begin{array}{l}\text { Discrepancy } \\
\text { case }(\%)\end{array}$} & \multicolumn{2}{|l|}{ Univariate } & \multicolumn{2}{|l|}{ Multivariate } \\
\hline & & & OR (95\% CI) & $p$ value & OR (95\% CI) & $p$ value \\
\hline \multicolumn{7}{|l|}{ Size (mm) } \\
\hline $1-10$ & 23 & $10(43.5)$ & 1 (Ref) & & 1 (Ref) & \\
\hline $11-20$ & 60 & $33(55.0)$ & $1.59(0.60-4.19)$ & 0.35 & $1.61(0.57-4.53)$ & 0.37 \\
\hline $21-30$ & 39 & $17(43.6)$ & $1.00(0.36-2.84)$ & 0.99 & $1.12(0.35-3.55)$ & 0.85 \\
\hline 31 & 24 & $12(50.0)$ & $1.30(0.41-4.10)$ & 0.65 & $1.34(0.37-4.85)$ & 0.66 \\
\hline \multicolumn{7}{|l|}{ Histology } \\
\hline Differentiated & 117 & $56(47.9)$ & 1 (Ref) & & 1 & \\
\hline Undifferentiated & 29 & $16(55.2)$ & $1.34(0.59-3.03)$ & 0.48 & $1.43(0.58-3.54)$ & 0.44 \\
\hline \multicolumn{7}{|l|}{ Location 1} \\
\hline Upper third & 17 & $4(23.5)$ & 1 (Ref) & & 1 (Ref) & \\
\hline Middle third & 77 & $36(46.8)$ & $2.85(0.85-9.54)$ & 0.09 & $2.67(0.77-9.29)$ & 0.12 \\
\hline Lower third & 52 & $32(61.5)$ & $5.20(1.49-18.2)$ & 0.01 & $4.02(1.10-14.7)$ & 0.04 \\
\hline \multicolumn{7}{|l|}{ Location 2} \\
\hline Lesser curvature & 60 & $24(40.0)$ & 1 (Ref) & & 1 (Ref) & \\
\hline Anterior wall & 31 & $15(48.4)$ & $1.41(0.59-3.37)$ & 0.06 & $1.47(0.55-3.93)$ & 0.44 \\
\hline Greater curvature & 15 & $11(73.3)$ & $4.12(1.18-14.5)$ & 0.03 & $3.31(0.86-12.7)$ & 0.08 \\
\hline Posterior wall & 39 & $21(53.8)$ & $1.75(0.78-3.95)$ & 0.18 & $1.82(0.77-4.30)$ & 0.18 \\
\hline Circumference & 1 & $1(100)$ & Not evaluated & & Not evaluated & \\
\hline \multicolumn{7}{|l|}{ Macroscopic type } \\
\hline Flat/depressed & 137 & $68(49.6)$ & 1 (Ref) & & 1 (Ref) & \\
\hline Elevated & 0 & 0 & Not evaluated & & Not evaluated & \\
\hline Mixed & 9 & $4(44.4)$ & $0.81(0.21-3.15)$ & 0.76 & $1.20(0.27-5.29)$ & 0.81 \\
\hline
\end{tabular}

$O R$ odds ratio, $C I$ confidence interval to be ignored. In this study, if the lesion was diagnosed as cUL1 in the active stage, no lesion resulted in pUL0. However, if the lesion was diagnosed as cUL1 in the healing or scarring stage, approximately $40-50 \%$ of the lesions resulted in pUL0. Given this high rate of overestimation of cUL in the healing and scarring stages, diagnostic ER might be a treatment option when UL was the only factor that did not meet the indications for ER. We previously reported that diagnostic ER for limited clinical submucosal invasive EGCs could avoid gastrectomy in $28.8 \%$ of patients [22]. Similar to the report, we assumed that diagnostic ER was performed on the following lesions, for which only cUL did not fulfill the indications for ER: (1) cT1a, differentiated type histology, size $>30 \mathrm{~mm}$, and cUL1 and (2) cT1a, undifferentiated type histology, size $\leq 20 \mathrm{~mm}$, and cUL1. As a result, $26.5 \%$ (57/170) of the lesions fulfilled the criteria for endoscopic curability A and B, which are considered curative [4]. Considering that the stomach can be preserved in approximately $30 \%$ of cases, diagnostic ER should be considered when UL is the only factor that does not meet the indications for ER. However, there is concern that this strategy of diagnostic ER may lead to an increase in difficult ER cases, as UL was reported to be a factor significantly associated with a long procedure time [23]. Tumor location in the lower third of the longitudinal axis of the stomach was significantly associated with overestimation of cUL. Approximately $60 \%$ of cUL1 cases located in the lower third were overestimated. Indentation in the antrum might induce misdiagnosis of fold convergence (Fig. 4). Given the higher rate of overestimation of cUL in the lower third and the technical ease of ER for lesions located in the lower third [23, 24], lesions in the lower third may be a good indication for diagnostic ER.

As for the pathological diagnosis, interobserver variability for the assessment of pUL has been reported [25]. Furthermore, it was reported that wide interval sections recommended for surgical specimens might underestimate lymphovascular and submucosal invasion [26]. In this study, out of 501 cUL1 lesions resected by ER, 182 (36.3\%) were diagnosed as pUL0, while out of 262 cUL1 lesions resected by surgery, $113(43.1 \%)$ were diagnosed as pUL0. Difference in the proportion of lesions diagnosed as cUL1 which resulted in pUL0 was nonsignificant between ER and surgical specimens. This result suggested that the section interval might not have a significant effect on the pathological diagnosis of UL.

This study has several limitations. First, this study had a retrospective design and was conducted at a single hospital, so selection bias exists. Second, many patients were referred to our hospital from other hospitals. Therefore, biopsies of the lesions were obtained from the previous hospital, which 
Table 6 Univariate and multivariate analyses of risk factors for overestimation of endoscopic ulcerative findings in the scarring stage

\begin{tabular}{|c|c|c|c|c|c|c|}
\hline & \multirow[t]{2}{*}{ Total } & \multirow[t]{2}{*}{ Discrepancy case (\%) } & \multicolumn{2}{|l|}{ Univariate } & \multicolumn{2}{|l|}{ Multivariate } \\
\hline & & & OR $(95 \%$ CI $)$ & $p$ value & OR (95\% CI) & $p$ value \\
\hline \multicolumn{7}{|l|}{ Size (mm) } \\
\hline $1-10$ & 65 & $28(43.1)$ & 1 (Ref) & & 1 (Ref) & \\
\hline $11-20$ & 207 & $78(37.7)$ & $0.80(0.45-1.41)$ & 0.44 & $0.91(0.50-1.63)$ & 0.75 \\
\hline $21-30$ & 176 & $60(34.1)$ & $0.68(0.38-1.22)$ & 0.20 & $0.77(0.42-1.41)$ & 0.40 \\
\hline 31 & 139 & $57(41.0)$ & $0.92(0.51-1.67)$ & 0.78 & $1.08(0.57-2.03)$ & 0.81 \\
\hline \multicolumn{7}{|l|}{ Histology } \\
\hline Differentiated & 445 & $168(37.8)$ & 1 (Ref) & & 1 (Ref) & \\
\hline Undifferentiated & 142 & $55(38.7)$ & $1.04(0.71-1.54)$ & 0.83 & $1.02(0.67-1.55)$ & 0.94 \\
\hline \multicolumn{7}{|l|}{ Location 1} \\
\hline Upper third & 137 & $43(31.4)$ & 1 (Ref) & & 1 (Ref) & \\
\hline Middle third & 367 & $132(36.0)$ & $1.23(0.81-1.87)$ & 0.34 & $1.25(0.81-1.93)$ & 0.31 \\
\hline Lower third & 83 & $48(57.8)$ & $3.00(1.70-5.28)$ & $<0.001$ & $2.79(1.55-5.02)$ & $<0.001$ \\
\hline \multicolumn{7}{|l|}{ Location 2} \\
\hline Lesser curvature & 261 & $92(35.2)$ & 1 (Ref) & & 1 (Ref) & \\
\hline Anterior wall & 110 & 47 (42.7) & $1.37(0.87-2.16)$ & 0.18 & $1.30(0.81-2.10)$ & 0.27 \\
\hline Greater curvature & 81 & $35(43.2)$ & $1.40(0.84-2.32)$ & 0.20 & $1.38(0.81-2.35)$ & 0.24 \\
\hline Posterior wall & 134 & 49 (36.6) & $1.06(0.69-1.63)$ & 0.80 & $1.17(0.74-1.84)$ & 0.50 \\
\hline Circumference & 1 & $0(0.0)$ & Not evaluated & & Not evaluated & \\
\hline \multicolumn{7}{|l|}{ Macroscopic type } \\
\hline Flat/depressed & 516 & $191(37.0)$ & 1 (Ref) & & 1 (Ref) & \\
\hline Elevated & 44 & $16(36.4)$ & $0.97(0.51-1.84)$ & 0.93 & $1.06(0.55-2.07)$ & 0.86 \\
\hline Mixed & 27 & $16(59.3)$ & $2.48(1.13-5.44)$ & 0.02 & $1.98(0.87-4.52)$ & 0.10 \\
\hline
\end{tabular}

$O R$ odds ratio, $C I$ confidence interval
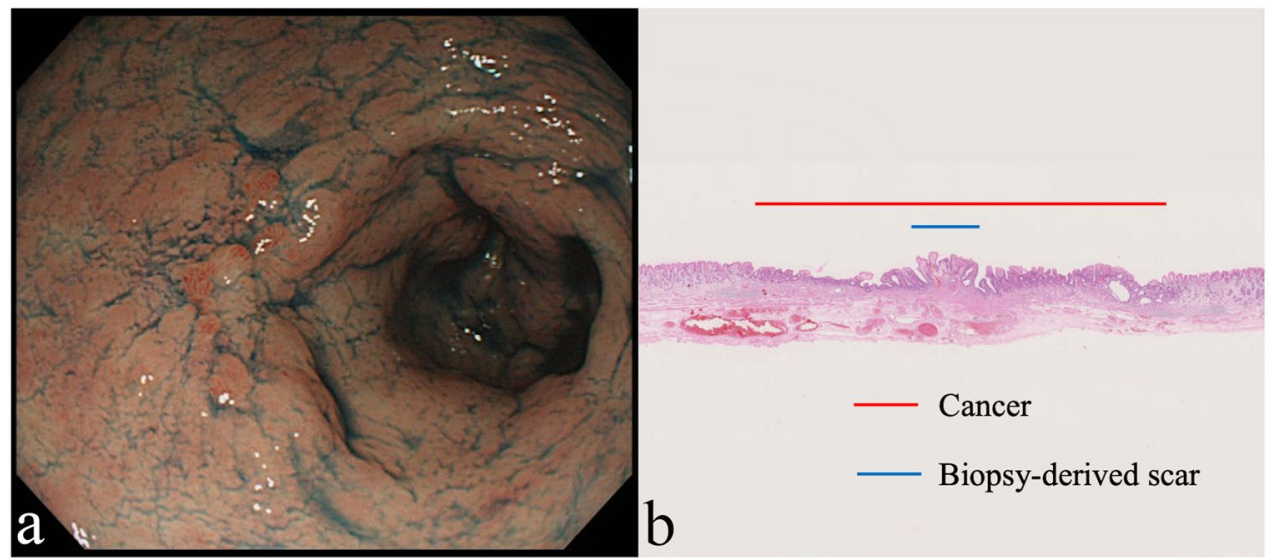

Fig. 4 a A 0-IIa + IIc lesion was located on the indentation in the antrum. This lesion was endoscopically diagnosed as ulcerative finding positive. b This lesion was pathologically diagnosed as ulcerative finding negative with biopsy-derived scar might lead to misdiagnosis of mucosal break induced by biopsy as cUL1. If images from the previous hospital prior to biopsy were available, cUL was evaluated with reference to them. However, we did not necessarily obtain images from the previous hospital. Third, the endoscopic diagnosis of UL is subjective. As this study was based on the endoscopic reports in our hospital, interobserver agreement for the assessment of cUL was not evaluated; therefore, this result may not be generalizable.
In conclusion, $38.7 \%$ of cUL1 in cT1 a EGC were overestimated, especially for lesions located in the lower third of the stomach. This discrepancy should be considered when managing cT1a EGC with UL, and diagnostic ER should be considered when UL is the only factor that does not meet the indications for ER. 


\section{Compliance with ethical standards}

Conflict of interest Dr. Takizawa reports personal fees from Takeda, personal fees from Otsuka, personal fees from EA Pharma, personal fees from Boston Scientific, personal fees from AstraZeneca, and personal fees from Taiho, outside the submitted work. Dr. Imai reports personal fees from Olympus, personal fees from Boston Scientific, personal fees from Chugai, and personal fees from EA Pharma, outside the submitted work. Dr. Bando reports personal fees from Kaken Pharmaceutical Co, and personal fees from Johnson and Johnson, outside the submitted work. Dr. Terashima reports personal fees from Taiho Pharmaceutical, personal fees from Chugai Pharma, personal fees from Ono Pharmaceutical, personal fees from BMS, personal fees from Yakult Honsha, personal fees from Takeda Pharma, personal fees from Eli Lilly, personal fees from Pfizer, personal fees from Daiichi Sankyo, grants and personal fees from Intuitive Surgical, personal fees from Johnson and Johnson, and personal fees from Medtornic, outside the submitted work. Dr. Ono reports personal fees from Otsuka, personal fees from EA Pharma, personal fees from Boston Scientific, personal fees from AstraZeneca, and personal fees from Olympus, outside the submitted work. The authors Yabuuchi, Kakushima, Kawata, Yoshida, Yamamoto, Kishida, Ito, Ishiwatari, Hotta, Matsubayashi, and Sugino have nothing to disclose.

Ethical approval All procedures followed were in accordance with the ethical standards of the responsible committee on human experimentation (institutional and national) and with the Helsinki Declaration of 1964 and later versions.

Informed consent Informed consent to be included in the study, or the equivalent, was obtained from all patients.

\section{References}

1. Tanaka M, Ono H, Hasuike N, Takizawa K. Endoscopic submucosal dissection of early gastric cancer. Digestion. 2008;77:23-8.

2. Gotoda T. Endoscopic resection of early gastric cancer. Gastric Cancer. 2007;10:1-11.

3. Ono H, Kondo H, Gotoda T, Shirao K, Yamaguchi H, Saito D, et al. Endoscopic mucosal resection for treatment of early gastric cancer. Gut. 2001;48:225-9.

4. Japanese Gastric Cancer Association. Japanese gastric cancer treatment guidelines 2018 (5th edition). Gastric Cancer. 2020. https://doi.org/10.1007/s10120-020-01042-y.

5. Yao K, Uedo N, Kamada T, Hirasawa T, Nagahama T, Yoshinaga $\mathrm{S}$, et al. Guidelines for endoscopic diagnosis of early gastric cancer. Dig Endosc. 2020;32:663-98.

6. Sakita T, Oguro Y, Takasu S, Fukutomi H, Miwa T, Yoshimori $\mathrm{M}$. Observations on the healing of ulcerations in early gastric cancer: the life cycle of the malignant ulcer. Gastroenterology. 1971;60:835-44.

7. Japanese Gastric Cancer Association. Japanese classification of gastric carcinoma: 3rd English edition. Gastric Cancer. 2011;14:101-12.

8. Kim JM, Sohn JH, Cho MY, Kim WH, Chang HK, Jung ES, et al. Pre- and post-ESD discrepancies in clinicopathologic criteria in early gastric cancer: the NECA-Korea ESD for early gastric cancer prospective study (N-Keep). Gastric Cancer. 2016;19:1104-13.
9. Shim CN, Song MK, Kang DR, Chung HS, Park JC, Lee H, et al. Size discrepancy between endoscopic size and pathologic size is not negligible in endoscopic resection for early gastric cancer. Surg Endosc. 2014;28:2199-207.

10. Choi J, Kim SG, Im JP, Kim JS, Jung HC. Endoscopic estimation of tumor size in early gastric cancer. Dig Dis Sci. 2013;58:2329-36.

11. Kuroki K, Oka S, Tanaka S, Yorita N, Hata K, Kotachi T, et al. Clinical significance of endoscopic ultrasonography in diagnosing invasion depth of early gastric cancer prior to endoscopic submucosal dissection. Gastric Cancer. 2020. https://doi.org/10.1007/ s10120-020-01100-5.

12. Nagahama T, Yao K, Imamura K, Kojima T, Ohtsu K, Chuman $\mathrm{K}$, et al. Diagnostic performance of conventional endoscopy in the identification of submucosal invasion by early gastric cancer: the "non-extension sign" as a simple diagnostic marker. Gastric Cancer. 2017;20:304-13.

13. Tsujii $\mathrm{Y}$, Kato M, Inoue T, Yoshii S, Nagai K, Fujinaga T, et al. Integrated diagnostic strategy for the invasion depth of early gastric cancer by conventional endoscopy and EUS. Gastrointest Endosc. 2015;82:452-9.

14. Abe S, Oda I, Shimazu T, Kinjo T, Tada K, Sakamoto T, et al. Depth-predicting score for differentiated early gastric cancer. Gastric Cancer. 2011;14:35-40.

15. Shim CN, Kim H, Kim DW, Chung HS, Park JC, Lee H, et al. Clinicopathologic factors and outcomes of histologic discrepancy between differentiated and undifferentiated types after endoscopic resection of early gastric cancer. Surg Endosc. 2014;28:2097-105.

16. Min BH, Kang KJ, Lee JH, Kim ER, Min YW, Rhee PL, et al. Endoscopic resection for undifferentiated early gastric cancer: focusing on histologic discrepancies between forceps biopsybased and endoscopic resection specimen-based diagnosis. Dig Dis Sci. 2014;59:2536-43.

17. Takao M, Kakushima N, Takizawa K, Tanaka M, Yamaguchi $\mathrm{Y}$, Matsubayashi H, et al. Discrepancies in histologic diagnoses of early gastric cancer between biopsy and endoscopic mucosal resection specimens. Gastric Cancer. 2012;15:91-6.

18. Park SM, Kim BW, Kim JS, Kim YW, Kim GJ, Ryu SJ. Can endoscopic ulcerations in early gastric cancer be clearly defined before endoscopic resection? A survey among endoscopists. Clin Endosc. 2017;50:473-8.

19. Lee J, Kim BW, Huh CW, Kim JS, Maeng LS. Endoscopic factors that can predict histological ulcerations in early gastric cancers. Clin Endosc. 2020;53:328-33.

20. Gotoda T, Yanagisawa A, Sasako M, Ono H, Nakanishi Y, Shimoda $\mathrm{T}$, et al. Incidence of lymph node metastasis from early gastric cancer: estimation with a large number of cases at two large centers. Gastric Cancer. 2000;3:219-25.

21. Hirasawa T, Gotoda T, Miyata S, Kato Y, Shimoda T, Taniguchi $\mathrm{H}$, et al. Incidence of lymph node metastasis and the feasibility of endoscopic resection for undifferentiated-type early gastric cancer. Gastric Cancer. 2009;12:148-52.

22. Fujiya K, Takizawa K, Tokunaga M, Kawata N, Hikage M, Makuuchi $\mathrm{R}$, et al. The value of diagnostic endoscopic submucosal dissection for patients with clinical submucosal invasive early gastric cancer. Gastric Cancer. 2018;21:124-32.

23. Suzuki H, Takizawa K, Hirasawa T, Takeuchi Y, Ishido K, Hoteya $\mathrm{S}$, et al. Short-term outcomes of multicenter prospective cohort study of gastric endoscopic resection: "Real-world evidence" in Japan. Dig Endosc. 2019;31:30-9.

24. Yano T, Hasuike N, Ono H, Boku N, Ogawa G, Kadota T, et al. Factors associated with technical difficulty of endoscopic submucosal dissection for early gastric cancer that met the expanded indication criteria: post hoc analysis of a multi-institutional 
prospective confirmatory trial (JCOG0607). Gastric Cancer. 2020;23:168-74.

25. Kwee RM, Kwee TC. Predicting lymph node status in early gastric cancer. Gastric Cancer. 2008;11:134-48.

26. Kim YI, Kook MC, Choi JE, Lee JY, Kim CG, Eom BW, et al. Evaluation of submucosal or lymphovascular invasion detection rates in early gastric cancer based on pathology section interval. J Gastric Cancer. 2020;20:165-75.
Publisher's Note Springer Nature remains neutral with regard to jurisdictional claims in published maps and institutional affiliations. 